\title{
Determination of $\mathrm{X}$-Ray Diffraction on the Phase Transformation of Microwave-Assisted Titanate Nanotubes during Thermal Treatment
}

\author{
Hsin-Hung Ou, Ching-Hui Liao, and Shang-Lien Lo \\ Research Center for Environmental Pollution Prevention and Control Technology, Graduate Institute of Environmental Engineering, \\ National Taiwan University, 71 Chou-Shan Rd., Taipei 106, Taiwan \\ Correspondence should be addressed to Shang-Lien Lo, sllo@ntu.edu.tw
}

Received 26 November 2009; Revised 20 April 2010; Accepted 21 April 2010

Academic Editor: Renzhi Ma

Copyright (๑) 2010 Hsin-Hung Ou et al. This is an open access article distributed under the Creative Commons Attribution License, which permits unrestricted use, distribution, and reproduction in any medium, provided the original work is properly cited.

Based on the determination of X-ray powder diffraction, this study aims to investigate the thermal effect on the phase transformation of microwave-assisted titanate nanotubes (MTNTs). The phase transformation is highly dependent on the intercalating amount of $\mathrm{Na}(\mathrm{I})$ within MTNTs and on the heating atmosphere. In other words, the presence of $\mathrm{Na}(\mathrm{I})$ favors the transformation of TNTs phase into $\mathrm{Na}_{2} \mathrm{Ti}_{6} \mathrm{O}_{13}$ whereas anatase phase selectively formed in the case of MTNTs with less $\mathrm{Na}(\mathrm{I})$ amount. Furthermore, $\mathrm{H}_{2}$ versus $\mathrm{O}_{2}$ is able to form anatase phase and establish a newly transformation pathway. The photocatalytic ability of the calcined MTNTs was also evaluated based on the observed rate constant of trichloroethylene degradation. In addition to anatase phase, the newly phase including $\mathrm{Na}_{2} \mathrm{Ti}_{6} \mathrm{O}_{13}$ and $\mathrm{Ti}_{2} \mathrm{O}_{3}$ with calcined MTNTs is able to photocatalyze trichloroethylene. MTNTs calcined with the presence of $\mathrm{H}_{2}$ also exhibit a superior photocatalytic performance to $\mathrm{P}_{2} 5 \mathrm{TiO}_{2}$.

\section{Introduction}

Titanate nanotubes (TNTs) have received engrossing interests owing to the vast applications including solar cells, photocatalysis, and electroluminescent hybrid device [1-5]. An overview regarding the fabrication, characterization, and application of TNTs was also demonstrated in [6]. In spite of the debate on the formation mechanism and chemical structure of TNTs, the application of TNT or even its derivates (nanoparticles and nanorods) on the photocatalytic field has been emerging [3-5]. Several studies have reported that TNTs without further treatment have no powerful photocatalytic ability [3, 4, 7]. Tsai and Teng [3] indicated that the thermal-treated TNTs versus P25 $\mathrm{TiO}_{2}$ exhibited a better performance on NO conversion. Similar result was indicated by Yu et al. [4] in terms of the microstructure of calcined TNTs. Furthermore, Štengl et al. [7] investigated the preparation, microstructure characterization, and photocatalytic activity of sodium titanate nanorods which were fabricated by using TNTs as materials. The single-crystalline $\mathrm{TiO}_{2}$ nanorods with highly activity and long-term stability have also been demonstrated in [8].
Our previous reports have characterized microwaveassisted TNTs (MTNTs) whose chemical structure was preferentially assigned for $\mathrm{Na}_{x} \mathrm{H}_{2-x} \mathrm{Ti}_{3} \mathrm{O}_{7}[5,9]$. The intercalation amount of $\mathrm{Na}(\mathrm{I})$ within MTNTs increases with enhancing applied level of irradiation powers during fabrication process [9]. The photocatalytic oxidation of aqueous ammonia over microwave-induced MTNTs was also examined recently in [5]. A specific degradation mechanism of photocatalytic ammonia over MTNTs was also proposed that the reaction of photocatalytic ammonia was not suffered from shielding effect. In the present study, the thermal effects including calcination temperature and atmosphere on the phase transformation of MTNTs were examined. The photocatalytic ability of calcined MTNTs towards gaseous trichloroethylene (TCE) degradation was also investigated.

\section{Experimental Section}

2.1. Preparation and Thermal Treatment of MTNTs. The fabrication of MTNTs is described in detail elsewhere in our previous studies in [5, 9]. In a typical process, the microwave digestion system (Ethos Touch Control, 
MILESTONE Corporation) with a double-walled consists of an inner Teflon liner and outer shell of high strength Ultem polyetherimide, was used. The applied temperature, power level, as well as treatment time, are programmable with an integrated computer. The slurry containing $0.6 \mathrm{~g}$ P25 $\mathrm{TiO}_{2}$ and $70 \mathrm{~mL} 10 \mathrm{~N} \mathrm{NaOH}$ was treated at $130^{\circ} \mathrm{C}$ for 3 hours under different microwave irradiation powers of 70,400 , and $700 \mathrm{~W}$ which are abbreviated as MTNTs$70 \mathrm{~W}$, MTNTs- $400 \mathrm{~W}$, and MTNTs-700 W, respectively. After microwave thermal treatment, the resulting powders were washed by $0.5 \mathrm{~N} \mathrm{HCl}$ until the $\mathrm{pH}$ of slurry achieved 7. The resulting powders were subsequently washed by deionized water repeatedly to remove the excess of $\mathrm{HCl}$ adhered on the surface of MTNTs. MTNTs were subsequently obtained after the filtration and dryied under the vacuum freeze dried for 20 hours $\left(-56^{\circ} \mathrm{C}\right.$; 100 200 Mtorr). Regarding the thermal treatment of TNTs, the experiments were conducted in the tubular oven under the atmospheres of $20 \% \mathrm{O}_{2} / 80 \% \mathrm{~N}_{2}$ and $20 \% \mathrm{H}_{2} / 80 \% \mathrm{~N}_{2}$ at the progressively elevated temperatures for 3 hours $\left(100,300,500\right.$, and $\left.700^{\circ} \mathrm{C}\right)$. The ramping rate was controlled at $2^{\circ} \mathrm{C} / \mathrm{min}$. The following powders subsequently cooled down to room temperature and were characterized by phase determinations.

2.2. XRPD Determinations of MTNTs. The X-ray powder diffractometer (XRPD) was employed to determine the crystalline phases of MTNTs after thermal treatment. The patterns were recorded from 5 to $70^{\circ}$ with a scan rate of $2^{\circ} /$ min by Philips X' Pert Pro MPD which was equipped with a CuK $\alpha$ X-ray source $(\lambda=1.5405 \AA)$ operating under a voltage of $40 \mathrm{kV}$ and a current of $30 \mathrm{~mA}$, respectively.

2.3. Photocatalytic Oxidation of TCE over MTNTs. Batch experiments of photocatalytic TCE over MTNTs were conducted in a flat-plate photoreactor, which has been described in detail in our previous publication [10]. MTNTs sample was coated on a silica board with the normalized concentration of $0.83 \mathrm{mg} / \mathrm{cm}^{2}$. The as-prepared photocatalyst was deposited on the bottom of the reactor without further treatment. The initial concentration of TCE was prepared at $70 \pm 2.5 \mu \mathrm{M}$, and the initial relative humidity and oxygen concentration were controlled at $25 \pm 2.5 \%$ and $3.53 \mathrm{mM}$, respectively. Illumination provided by three $8 \mathrm{~W}$ black-light fluorescent lamps principally emits at $365 \mathrm{~nm}$ with the light intensity of $2.34 \pm 0.23 \mathrm{~mW} / \mathrm{cm}^{2}$. The concentration of TCE, under a series of time sequence during photocatalytic experiments, was quantified via the manual injection into the gas chromatograph (5890II) equipped with the flame ionization detector. The photocatalytic ability of TNTs was quantitatively evaluated by the corresponding observed rate constants $\left(k_{\mathrm{obs}}\right)$ of TCE degradation.

\section{Results and Discussion}

3.1. XRD Determinations on the MTNTs after Thermal Treatment. XRPD determination was used to investigate the phase of MTNTs after calcination at increasing temperatures $\left(100 \sim 700^{\circ} \mathrm{C}\right)$ under the atmosphere of either $\mathrm{O}_{2}$ or $\mathrm{H}_{2}$. In

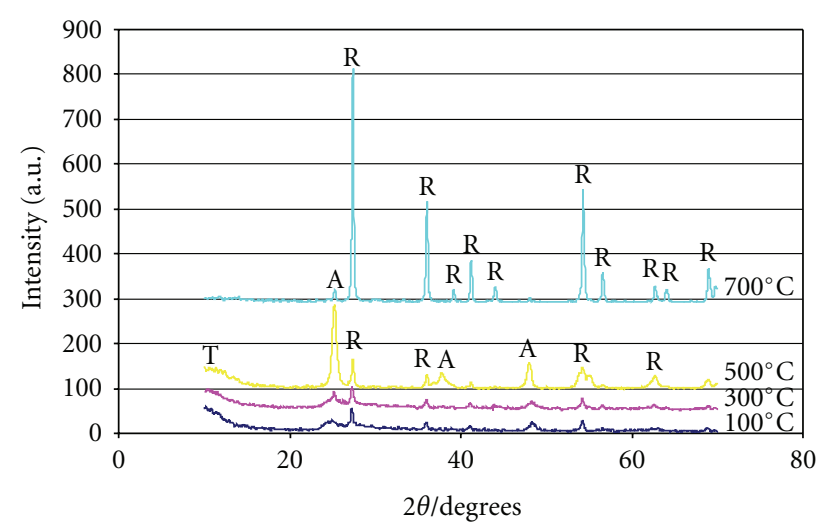

A: Anatase

R: Rutile

T: TNTs

(a)

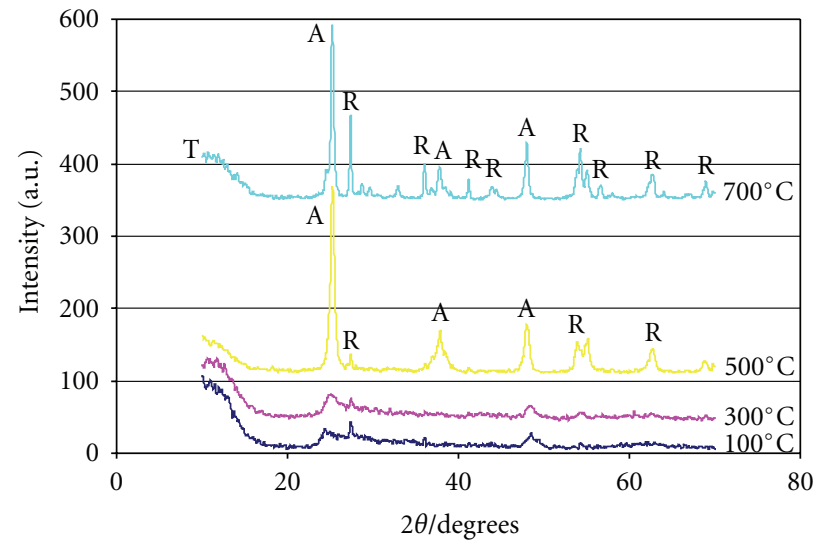

A: Anatase

R: Rutile

T: TNTs

(b)

FIGURE 1: XRPD patterns of MTNTs-70W calcined at elevated temperatures under the atmosphere of (a) $20 \% \mathrm{O}_{2} / 80 \% \mathrm{~N}_{2}$ and (b) $20 \% \mathrm{H}_{2} / 80 \% \mathrm{~N}_{2}$.

the following materials, samples indexed as $\mathrm{MTNTs}_{\mathrm{X}-\mathrm{Y}^{\circ} \mathrm{C}}$ represent MTNTs calcined at $\mathrm{Y}^{\circ} \mathrm{C}$ under $\mathrm{X}$ atmosphere. Figures 1-3 show the dependence of phase change of MTNTs on the heating temperature and atmosphere. Either in the presence of $\mathrm{O}_{2}$ and $\mathrm{H}_{2}$, no appreciable change of MTNTs phase was observed as the heating temperature was lower than $300^{\circ} \mathrm{C}$. In addition, an interesting phenomenon was observed that the phase transformation of MTNTs-70W begins at $500^{\circ} \mathrm{C}$ whereas no phase change was observed for MTNTs-700W calcined at the same temperature. According to our previous report $[5,9]$, a high level of microwave irradiation during fabrication process favors the intercalation of $\mathrm{Na}(\mathrm{I})$ into MTNTs. In other words, the intercalated $\mathrm{Na}(\mathrm{I})$ is advantageous to the stability of MTNTs during thermal treatment. 
As for MTNTs-70W, anatase phase dominates for either MTNTs- $70 \mathrm{~W}_{\mathrm{O} 2-500^{\circ} \mathrm{C}}$ (Figure $1(\mathrm{a})$ ) or MTNTs-70W $\mathrm{H} 2-500^{\circ} \mathrm{C}$ (Figure 1(b)), and an increasing temperature results in the transformation of anatase phase into rutile

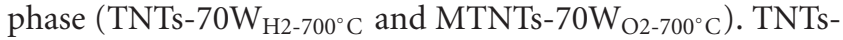
$70 \mathrm{~W}_{\mathrm{H} 2-700^{\circ} \mathrm{C}}$ versus MTNTs- $70 \mathrm{~W}_{\mathrm{O} 2-700^{\circ} \mathrm{C}}$ exhibits a stronger intensity of the anatase phase, suggesting that $\mathrm{H}_{2}$ is beneficial to maintain anatase phase. In the case of MTNTs-400W (Figure 2), anatase phase along with a trace amount of rutile phase exists in MTNTs- $400 \mathrm{~W}_{\mathrm{O} 2-500^{\circ} \mathrm{C}}$ and an increase in temperature to $700^{\circ} \mathrm{C}$ results in the formation of $\mathrm{Na}_{2} \mathrm{Ti}_{6} \mathrm{O}_{13}$ at the expense of anatase phase (Figure 2(a)). Comparatively, TNTs phase still dominates at MTNTs $-400 \mathrm{~W}_{\mathrm{H}-500^{\circ} \mathrm{C}}$ whereas TNTs- $400 \mathrm{~W}_{\mathrm{H} 2-700^{\circ} \mathrm{C}}$ presents the relatively significant anatase, rutile, and $\mathrm{Na}_{2} \mathrm{Ti}_{6} \mathrm{O}_{13}$ phase (Figure 2(b)). This result not only corresponds to the aforementioned conclusion in that $\mathrm{H}_{2}$ helps to establish anatase phase within MTNTs but also indicates that $\mathrm{O}_{2}$ provides the prevailing ability to transform TNTs phase. Regarding the phase transformation of TNTs-700W, $\mathrm{Na}_{2} \mathrm{Ti}_{6} \mathrm{O}_{13}$ is the predominant phase in MTNTs- $700 \mathrm{~W}_{\mathrm{O} 2-700^{\circ} \mathrm{C}}$ (Figure 3(a)) whereas $\mathrm{Ti}_{2} \mathrm{O}_{3}$ and $\mathrm{Na}_{2} \mathrm{Ti}_{6} \mathrm{O}_{13}$ with trace anatase phase appear in the $\mathrm{TNTs}^{-} 700 \mathrm{~W}_{\mathrm{H} 2-700^{\circ} \mathrm{C}}$ (Figure $3(\mathrm{~b})$ ). These results reveal that the presence of $\mathrm{H}_{2}$ leads to a selective transformation pathway as MTNTs was intercalated with abounding amount of $\mathrm{Na}(\mathrm{I})$.

Usually, for pure anatase $\mathrm{TiO}_{2}$ samples, the rutile phase starts to appear at ca. $700^{\circ} \mathrm{C}$ [11]. Tsai and Teng [3] have also indicated that the rutile phase arose at $900^{\circ} \mathrm{C}$ as far as the traditional TNTs are concerned. In our study, rutile phase can be observed as MTNTs were treated at $500^{\circ} \mathrm{C}$ under $\mathrm{O}_{2}$ atmosphere (Figure $1(\mathrm{a})$ ), which suggests that $\left[\mathrm{TiO}_{6}\right]$ octahedra are easy to be transformed. This result can be ascribed to the application of microwave irradiation during fabrication process of MTNTs. Furthermore, the appearance of $\mathrm{Na}_{2} \mathrm{Ti}_{6} \mathrm{O}_{13}$ can be derived from the dehydration of $\mathrm{Na}_{x} \mathrm{Ti}_{2-x} \mathrm{Ti}_{2} \mathrm{O}_{5}\left(\mathrm{H}_{2} \mathrm{O}\right)$ and is found to be more abundant for TNTs washed and suspended under more basic conditions, that is, more $\mathrm{Na}(\mathrm{I})$ was intercalated into TNTs $[12,13]$. The demonstration in our result is consistent to the results of above researches and again confirms that the applied microwave irradiation favors the intercalation of $\mathrm{Na}(\mathrm{I})$ into MTNTs structure.

\subsection{Photocatalytic Oxidation of Gaseous TCE over MTNTs.} Figure 4 demonstrates the dependence of $k_{o b s}$ on the heating temperature and atmosphere. No TCE degraded over MTNTs without thermal treatment, suggesting that MTNTs have no powerful ability to TCE degradation. This result corresponds to the XRPD determination that anatase phase, a major crystalline phase responsible for organic degradation, arose at the heating temperature higher than $300^{\circ} \mathrm{C}$.

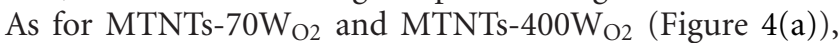
$k_{\text {obs }}$ increase with increasing calcination temperature until $500^{\circ} \mathrm{C}$. A further increase in heating temperature to $700^{\circ} \mathrm{C}$ results in a decrease in $k_{\text {obs }}$. The phenomenon can be ascribed to the absence or low crystallization of anatase phase as MTNTs calcined at $700^{\circ} \mathrm{C} . \mathrm{Na}_{2} \mathrm{Ti}_{6} \mathrm{O}_{13}$ phase appearing in MTNTs- $700 \mathrm{~W}_{\mathrm{O} 2-700^{\circ} \mathrm{C}}$ is also effective to the degradation

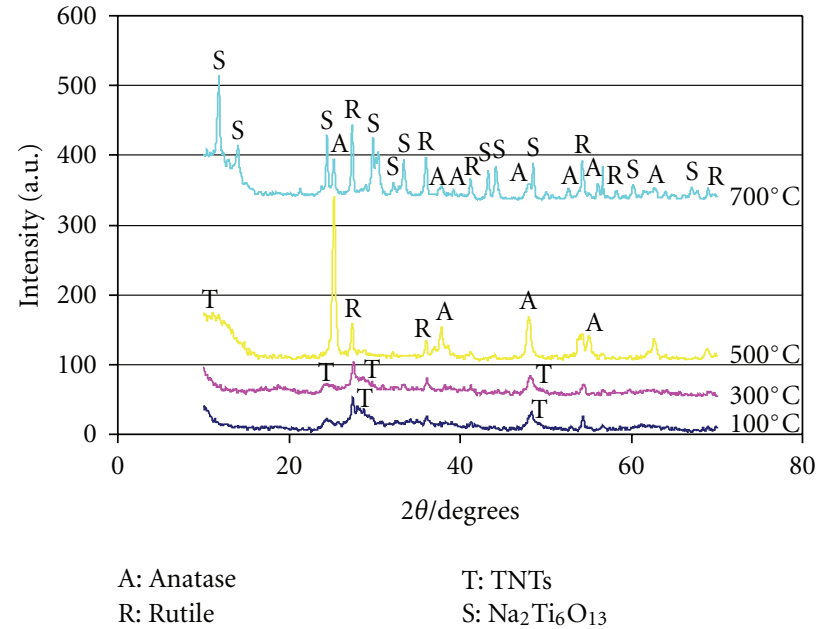

(a)

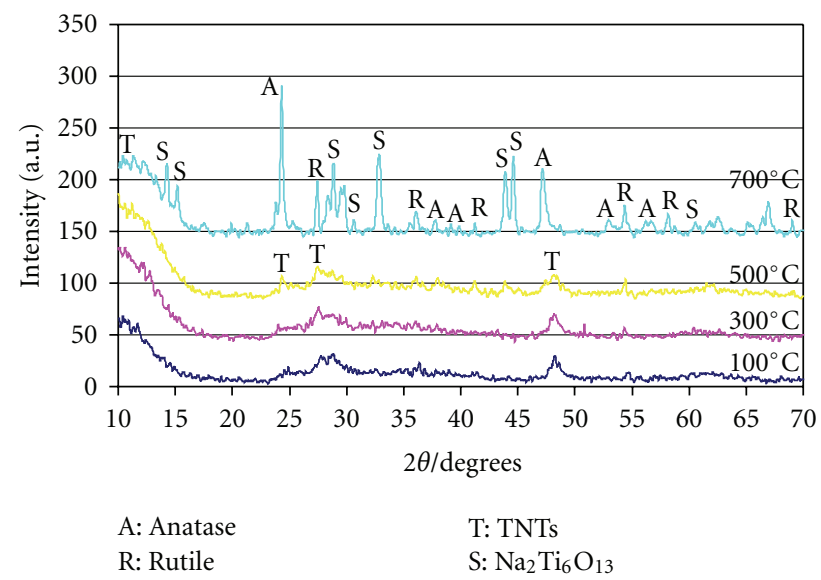

(b)

FIGURE 2: XRPD patterns of MTNTs-400W calcined at elevated temperatures under the atmosphere of (a) 20\% $\mathrm{O}_{2} / 80 \% \mathrm{~N}_{2}$ and (b) $20 \% \mathrm{H}_{2} / 80 \% \mathrm{~N}_{2}$.

of TCE despite the $k_{\text {obs }}$ value $\left(0.74 \pm 0.15 \mathrm{~min}^{-1}\right)$ is not excellent. The photocatalytic ability of $\mathrm{Na}_{2} \mathrm{Ti}_{6} \mathrm{O}_{13}$ can be attributed to the corresponding tunnel structure, which provides a number of active sites and has a significant effect on the efficiency of separation of the irradiated generated photos $[14,15]$. Regarding the MTNTs calcined under $\mathrm{H}_{2}$ atmosphere (Figure $4(\mathrm{~b})$ ), $k_{\mathrm{obs}}$ increase with an increase in calcination temperature no matter which type of MTNTs was investigated. An interesting result was also noticed that TNTs- $700 \mathrm{~W}_{\mathrm{H} 2-700^{\circ} \mathrm{C}}$ without the presence of anatase phase has $k_{\mathrm{obs}}$ of $3.29 \pm 0.27 \mathrm{~min}^{-1}$ (Figure 4(b)). In other words, $\mathrm{Ti}_{2} \mathrm{O}_{3}$ and $\mathrm{Na}_{2} \mathrm{Ti}_{6} \mathrm{O}_{13}$ are able to photocatalyze TCE. Most significantly, MTNTs- $70 \mathrm{~W}_{\mathrm{H} 2-700^{\circ} \mathrm{C}}$ and MTNTs- $400 \mathrm{~W}_{\mathrm{H} 2-700^{\circ} \mathrm{C}}$ present superior performances to that P25 catalysts $\left(6.63 \pm 0.18 \mathrm{~min}^{-1}\right)$ do. This result may attribute to the different pore structure, exhibited crystal phase of TNTs samples. Further experiments on the pore size distribution of MTNTs after thermal treatment are under investigation. 


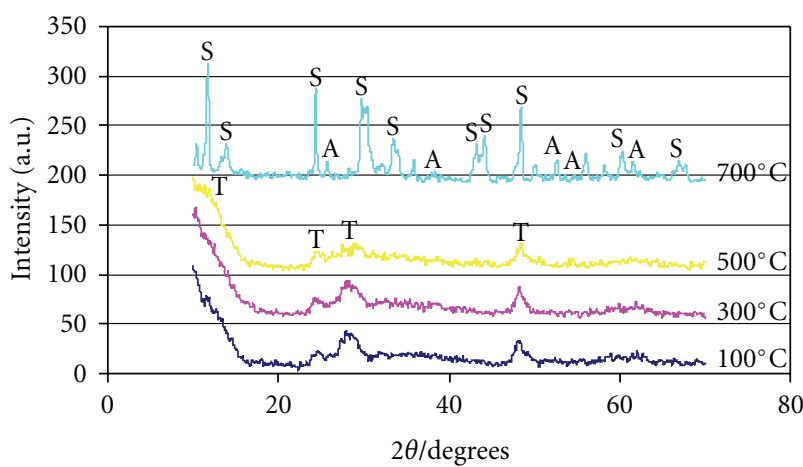

A: Anatase
T: TNTs
S: $\mathrm{Na}_{2} \mathrm{Ti}_{6} \mathrm{O}_{13}$

(a)

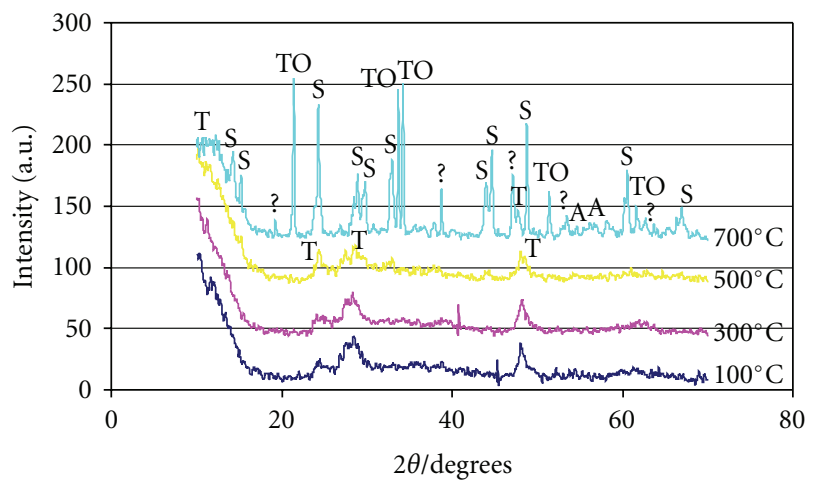

$\begin{array}{ll}\text { A: Anatase } & \text { S: } \mathrm{Na}_{2} \mathrm{Ti}_{6} \mathrm{O}_{13} \\ \text { T: TNTs } & \text { TO: } \mathrm{TI}_{2} \mathrm{O}_{3}\end{array}$

(b)

FIGURE 3: XRPD patterns of MTNTs-700W calcined at elevated temperatures under the atmosphere of (a) $20 \% \mathrm{O}_{2} / 80 \% \mathrm{~N}_{2}$ and (b) $20 \% \mathrm{H}_{2} / 80 \% \mathrm{~N}_{2}$.

In addition to the contribution of anatase phase in the photocatalytic reaction, the photocatalytic ability can be attributed to the well-known interparticle electron process (IPET process) $[16,17]$. The band gaps between two coupled semiconductors/crystal phases establish a selective pathway for irradiated electrons to migrate. This candidate pathway is able to result in an efficient separation between irradiated photoholes and photoelectrons. Therefore, more hydroxyl radicals $(\mathrm{OH} \bullet)$ are expected to produce with IPET process. This effect can be evidenced in terms of the comparison of $k_{\mathrm{obs}}$ between MTNTs- $70 \mathrm{~W}_{\mathrm{H} 2-500^{\circ} \mathrm{C}}$

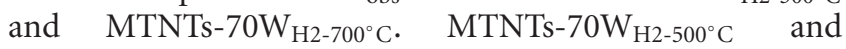
MTNTs- $70 \mathrm{~W}_{\mathrm{H} 2-700^{\circ} \mathrm{C}}$ exhibit a comparative intensity of anatase phase (Figure 1(b)) but the degradation of TCE is better for TNTs- $70 \mathrm{~W}_{\mathrm{H} 2-700^{\circ} \mathrm{C}}$ versus $\mathrm{TNTs}-70 \mathrm{~W}_{\mathrm{H} 2-500^{\circ} \mathrm{C} \text {. This }}$ is owing to the coexistence of anatase and rutile phases in

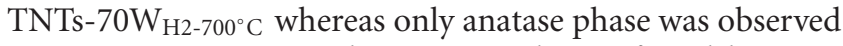

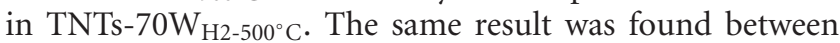
the cases of TNTs- $70 \mathrm{~W}_{\mathrm{H} 2-700^{\circ} \mathrm{C}}$ and TNTs- $400 \mathrm{~W}_{\mathrm{H} 2-700^{\circ} \mathrm{C}}$ that TNTs- $400 \mathrm{~W}_{\mathrm{H} 2-700^{\circ} \mathrm{C}}$ exhibits diversified phases including

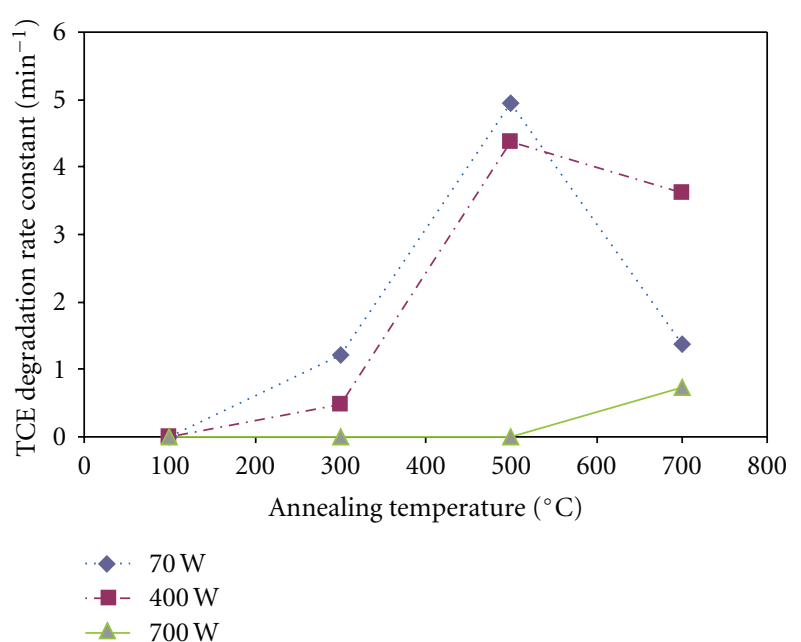

(a)
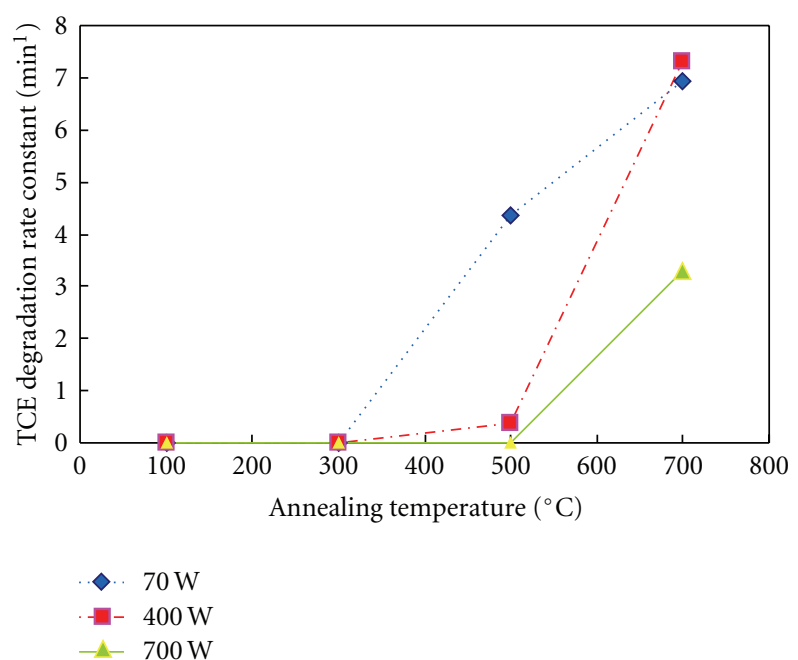

(b)

FIgURE 4: The dependence of $k_{\text {obs }}$ on the MTNTs calcined at the progressively temperatures $\left(25 \sim 700^{\circ} \mathrm{C}\right)$ under the atmospheres of $20 \% \mathrm{O}_{2} / 80 \% \mathrm{~N}_{2}$ and (b) $20 \% \mathrm{H}_{2} / 80 \% \mathrm{~N}$.

anatase, rutile, and $\mathrm{Na}_{2} \mathrm{Ti}_{6} \mathrm{O}_{13}$ (Figure 2(b)). However, despite TNTs- $700 \mathrm{~W}_{\mathrm{H} 2-700^{\circ} \mathrm{C}}$ includes four crystal types, the contribution of IPET process is not manifested since the prevailing oxidant phase (anatase phase) is weak (Figure 3(b)).

\section{Conclusions}

MTNTs with less amount of $\mathrm{Na}(\mathrm{I})$ prefer to form anatase phase after thermal treatment. In contrast, $\mathrm{Na}_{2} \mathrm{Ti}_{6} \mathrm{O}_{13}$ is a predominant phase as MTNTs with abounding amount of $\mathrm{Na}(\mathrm{I})$ was thermally treated. The presence of $\mathrm{H}_{2}$ during thermal treatment establishes a selective crystalline pathway in which $\mathrm{Ti}_{2} \mathrm{O}_{3}$ phase forms for MTNTs with abounding amount of $\mathrm{Na}(\mathrm{I})$. Regarding the TCE degradation over MTNTs, both the presence of anatase phase and IPET process contribute to the TCE degradation. Despite not all calcined 
MTNTs are superior to commercial P25 TiO 2 in TCE degradation, MTNTs fabricated via microwave hydrothermal process exhibit a well-defined behavior during thermal treatment. We are confident that some insight into the nature and behavior of MTNTs during thermal treatment can be useful for designing some novel catalysts.

\section{Acknowledgment}

The authors would like to thank the National Science Council of the Republic of China for financially supporting this research under Contract no. NSC 95-2221-E-002-143-MY3.

\section{References}

[1] L. Yu and X. Zhang, "Hydrothermal synthesis and characterization of vanadium oxide/titanate composite nanorods," Materials Chemistry and Physics, vol. 87, no. 1, pp. 168-172, 2004.

[2] R. Dominko, E. Baudrin, P. Umek, D. Arčon, M. Gaberšček, and J. Jamnik, "Reversible lithium insertion into $\mathrm{Na}_{2} \mathrm{Ti}_{6} \mathrm{O}_{13}$ structure," Electrochemistry Communications, vol. 8, no. 4, pp. 673-677, 2006.

[3] C.-C. Tsai and H. Teng, "Regulation of the physical characteristics of titania nanotube aggregates synthesized from hydrothermal treatment," Chemistry of Materials, vol. 16, no. 22, pp. 4352-4358, 2004.

[4] J. Yu, H. Yu, B. Cheng, and C. Trapalis, "Effects of calcination temperature on the microstructures and photocatalytic activity of titanate nanotubes," Journal of Molecular Catalysis A, vol. 249, no. 1-2, pp. 135-142, 2006.

[5] H.-H. Ou, C.-H. Liao, Y.-H. Liou, J.-H. Hong, and S.L. Lo, "Photocatalytic oxidation of aqueous ammonia over microwave-induced titanate nanotubes," Environmental Science and Technology, vol. 42, no. 12, pp. 4507-4512, 2008.

[6] H.-H. Ou and S.-L. Lo, "Review of titania nanotubes synthesized via the hydrothermal treatment: fabrication, modification, and application," Separation and Purification Technology, vol. 58, no. 1, pp. 179-191, 2007.

[7] V. Štengl, S. Bakardjieva, J. Šubrt, et al., "Sodium titanate nanorods: preparation, microstructure characterization and photocatalytic activity," Applied Catalysis B, vol. 63, no. 1-2, pp. 20-30, 2006.

[8] Y. Yu and D. Xu, "Single-crystalline $\mathrm{TiO}_{2}$ nanorods: highly active and easily recycled photocatalysts," Applied Catalysis B, vol. 73, no. 1-2, pp. 166-171, 2007.

[9] H. H. Ou, S. L. Lo, and Y. H. Liou, "Microwave-induced titanate nanotubes and the corresponding behaviour after thermal treatment," Nanotechnology, vol. 18, no. 17, Article ID 175702, 2007.

[10] H.-H. Ou and S.-L. Lo, "Photocatalysis of gaseous trichloroethylene (TCE) over $\mathrm{TiO}_{2}$ : the effect of oxygen and relative humidity on the generation of dichloroacetyl chloride (DCAC) and phosgene," Journal of Hazardous Materials, vol. 146, no. 1-2, pp. 302-308, 2007.

[11] J.-G. Yu, H.-G. Yu, B. Cheng, X.-J. Zhao, J. C. Yu, and W.K. Ho, "The effect of calcination temperature on the surface microstructure and photocatalytic activity of $\mathrm{TiO}_{2}$ thin films prepared by liquid phase deposition," Journal of Physical Chemistry B, vol. 107, no. 50, pp. 13871-13879, 2003.
[12] J.-N. Nian and H. Teng, "Hydrothermal synthesis of singlecrystalline anatase $\mathrm{TiO}_{2}$ nanorods with nanotubes as the precursor," Journal of Physical Chemistry B, vol. 110, no. 9, pp. 4193-4198, 2006.

[13] C.-C. Tsai and H. Teng, "Structural features of nanotubes synthesized from $\mathrm{NaOH}$ treatment on $\mathrm{TiO}_{2}$ with different post-treatments," Chemistry of Materials, vol. 18, no. 2, pp. 367-373, 2006.

[14] Y. Inoue, T. Niiyama, and K. Sato, "Photocatalysts using hexa- and octa-titanates with different tunnel space for water decomposition," Topics in Catalysis, vol. 1, no. 1-2, pp. 137144, 1994.

[15] Y. Inoue, T. Kubokawa, and K. Sato, "Photocatalytic activity of alkali-metal titanates combined with $\mathrm{Ru}$ in the decomposition of water," Journal of Physical Chemistry, vol. 95, no. 10, pp. 4059-4063, 1991.

[16] N. Serpone, P. Maruthamuthu, P. Pichat, E. Pelizzetti, and H. Hidaka, "Exploiting the interparticle electron transfer process in the photocatalysed oxidation of phenol, 2-chlorophenol and pentachlorophenol: chemical evidence for electron and hole transfer between coupled semiconductors," Journal of Photochemistry and Photobiology A, vol. 85, no. 3, pp. 247-255, 1995.

[17] H.-H. Ou, S.-L. Lo, and C.-H. Wu, "Exploring the interparticle electron transfer process in the photocatalytic oxidation of 4chlorophenol," Journal of Hazardous Materials, vol. 137, no. 3 , pp. 1362-1370, 2006. 

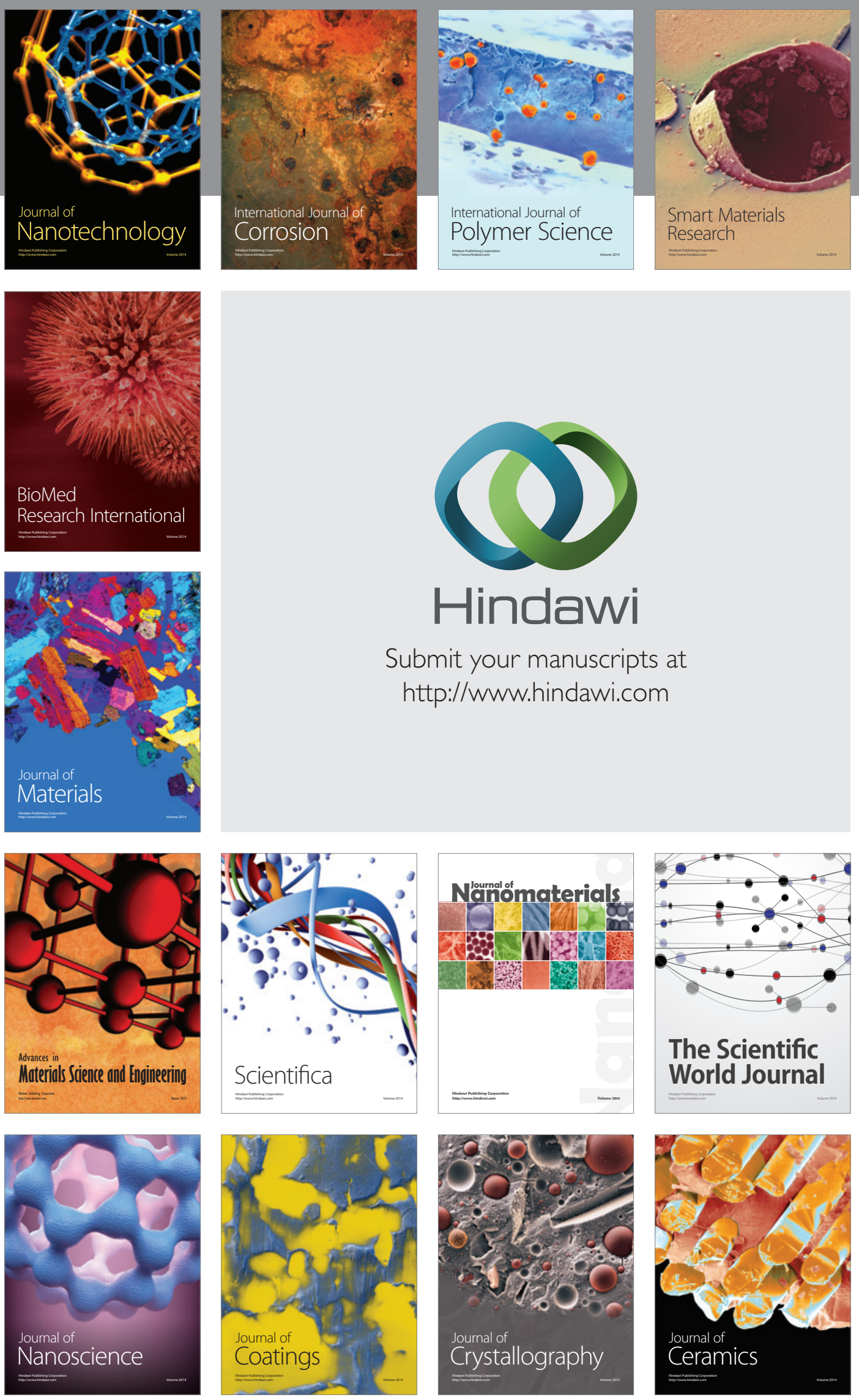

The Scientific World Journal

Submit your manuscripts at

http://www.hindawi.com

\section{World Journal}

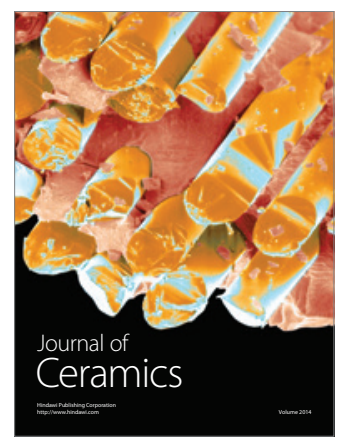

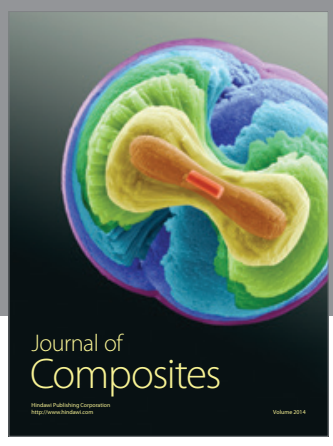
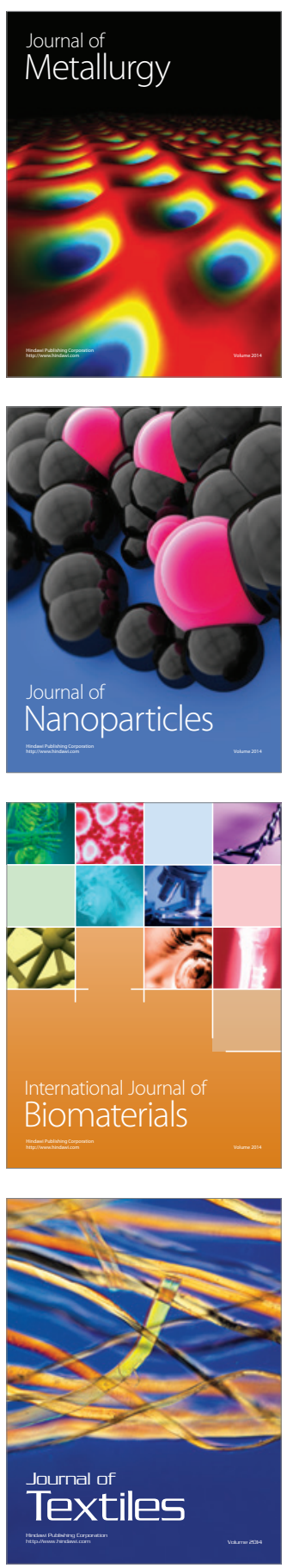